\title{
Caracterización fenotípica de la cepa N2 de Caenorhabditis elegans como un modelo en enfermedades neurodegenerativas
}

\author{
Phenotypic characterization of the N2 strain of Caenorhabditis elegans as \\ a model in neurodegenerative diseases
}

Parada Ferro Laura Katerine ${ }^{1}$ Gualteros Bustos Andrea Viviana ${ }^{1}$, Sánchez Mora Ruth Mélida²

\section{Resumen}

El nematodo C. elegans se estableció desde 1960, gracias al biólogo sudafricano Sydney Brenner, como un organismo modelo en investigación. Sus cualidades biológicas permiten mejorar la visión y comprensión de patologías en los seres humanos y otros seres pluricelulares; además, sus fenotipos claros y observables lo convierten en un organismo adecuado para el estudio básico de enfermedades neurodegenerativas, inmunológicas y procesos cancerígenos. Objetivo. Analizar las características fenotípicas de la cepa silvestre N2 de C. elegans para su posterior uso como modelo de tamizaje en el laboratorio de Biotecnología y Genética (Universidad Colegio Mayor de Cundinamarca). Materiales y Métodos. El nematodo fue cultivado y crecido en el medio NGM con la cepa E. coli OP50. La cepa N2 fue sincronizada para obtener huevos y posteriormente larvas L1. Se estandarizaron los ensayos de longevidad, reproducción, longitud y estrés térmico. Resultados. La caracterización fenotípica de la cepa N2 de C. elegans presentó: una longevidad de 16 a 22 días, una reproducción promedio de 225 crías, la longitud del nematodo fue de $1100 \pm 50 \mu \mathrm{m}$ y la supervivencia bajo estrés térmico evaluada en las dos etapas de desarrollo del nematodo es muy reducida a $37^{\circ} \mathrm{C}$ en comparación de $35^{\circ} \mathrm{C}$; ademas, los nematodos fueron más resistentes al primer día de adulto joven en comparacion con el sexto día de adulto. Conclusiones. Los resultados aportados por este estudio permiten sugerir que las características fenotípicas del nematodo analizadas se encuentran dentro de lo reportado en la literatura, por lo cual es viable usarlo como como modelo biológico en diferentes ensayos tal como lo reportan otros estudios.

Palabras claves: C. elegans, Neurodegenerativa, Longevidad, Reproducción, Estadios larvarios. 


\begin{abstract}
The nematode C. elegans was established since 1960, thanks to the South African biologist Sydney Brenner, as a model organism in research. Their biological qualities allow to improve the vision and understanding of pathologies in human and other multicellular beings; In addition, its clear and observable phenotypes make it a suitable organism for the basic study of neurodegenerative, immunological diseases and carcinogenic processes. Objective. To analyze the phenotypic characteristics of the $\mathrm{C}$. elegans N2 wild strain for later use as a screening model in the Biotechnology and Genetics Laboratory (Colegio Mayor de Cundinamarca University). Materials and Methods. The nematode was grown and grown in the NGM medium with the strain E. coli OP50. The N2 strain was synchronized to obtain eggs and later L1 larvae. The tests of longevity, reproduction, length and thermal stress were standardized. Results. The phenotypic characterization of the $\mathrm{N} 2$ strain of C. elegans presented a longevity of 16 to 22 days, an average reproduction of 225 offspring, the length of the nematode was $1100 \pm 50 \mu \mathrm{m}$ and the survival under thermal stress evaluated in the two Development stages of the nematode is greatly reduced at $37^{\circ} \mathrm{C}$ compared to $35^{\circ} \mathrm{C}$; In addition, nematodes were more resistant to the first day of young adult compared to the sixth day of adulthood. Conclusions. The results of this study suggest that the phenotypic characteristics of the nematode analyzed are within the literature, so it is feasible to use it as a biological model in different trials as reported in other studies.
\end{abstract}

Keywords: C. elegans, Neurodegenerative, Longevity, Reproduction, Larval stages.

\section{Introducción}

El nematodo Caenorhabditis elegans ha llegado a convertirse en un modelo animal importante en diversos campos, tales como: la neurobiología $(1,2)$, biología del desarrollo (3), la genética (4-6), la toxicología biomédica (7-9), la neurociencia (10-13), en el estudio de cáncer (14), entre otros; debido a que posee genes, vías y proteínas homólogas en el ser humano, además de ser el modelo en el cual se descubrió la muerte celular programada (15).

C. elegans posee una serie de características que lo hacen relevante y exitoso como modelo para la investigación biológica, algunas de estas particularidades son: su genoma bien caracterizado; la facilidad de mantenimiento; un cuerpo pequeño (8); la posibilidad de mantener en condiciones de laboratorio con una dieta de Escherichia coli OP50, lo que resulta ser bastante económico y fácil; su corto ciclo de vida 3 días (ver Figura 1A); un gran número de crías $(>300)$ que permite la producción a gran escala de estos animales dentro de un corto periodo de tiempo; la practicidad y simplicidad al momento de estudiar el nematodo, pues el adulto hermafrodita tiene sólo 959 células somáticas que forman diferentes órganos y tejidos incluyendo el músculo, la hipodermis (piel), sistema reproductor, glándulas, y un sistema nervioso que contiene 302 neuronas (16).

El uso de este nematodo se ha convertido en una herramienta de gran alcance para la industria farmacéutica, la explicación de problemas científicos y es una ayuda para definir nuevos puntos de entrada terapéuticos; sin embargo, en Colombia son pocos los estudios que se llevan a cabo utilizando dicho modelo.

Cabe resaltar que una de las aplicaciones más conocidas de C. elegans es su uso para el estudio de enfermedades neurodegenerativas cuyo tratamiento no ha sido plenamente identificado. No obstante, en su mayoría, los mecanismos subyacentes a la disfunción y muerte neuronal en estos trastornos siguen sin estar claros pese a la identificación de 
genes relacionados con enfermedades neurodegenerativas relevantes, tales como: Alzheimer (EA), Parkinson (EP), síndrome de disfunción cognitiva, entre otros. Es relevante mencionar que es difícil encontrar tratamientos para estas enfermedades ya que no están disponibles o resultan ser ineficaces (17).

En el presente estudio se utilizó la cepa silvestre de C. elegans $\mathrm{N} 2$; se analizaron aspectos fenotípicos como la longevidad, la reproducción, la longitud del cuerpo y el estrés térmico.

\section{Materiales y métodos}

\section{Mantenimiento de C. elegans cepa silvestre N2}

Para el mantenimiento del nematodo se realizó la preparación del medio NGM (Nematode Growth Medium), utilizado para el crecimiento de nematodos y el mantenimiento de la E. coli OP50, se tomó como referencia el protocolo propuesto por el Caenorhabditis Genétics Center (CGC) de la Universidad de Minnesota,en el cual se utiliza $\mathrm{NaCl}$, agar y peptona disueltos en agua para ser autoclavados y posteriormente enriquecerse con $\mathrm{CaCl} 21 \mathrm{M}$, colesterol más etanol y el buffer KPO4 1M pH 6.0 preparado con $\mathrm{KH} 2 \mathrm{PO} 4, \mathrm{~K} 2 \mathrm{HPO} 4$ en agua destilada (18).

La E. coli OP50 puede ser mantenida en agar LB o en caldo $\mathrm{LB}$ se deja incubar por 24 horas a $37^{\circ} \mathrm{C}$ y se pueden mantener a $4^{\circ} \mathrm{C}$ durante meses (18).

\section{Reactivación Cultivo de C. elegans cepa silvestre N2}

La cepa N2 de C. elegans y E. coli OP50 fue donada por la Dra. Andrea Calixto de la Universidad Mayor de Chile. Para la reactivación del cultivo se traspasaron fragmentos de agar de las cajas donde venía la cepa N2 cuyos nematodos se encontraban en etapa Dauer a 5 cajas NGM completamente nuevas y con E. coli OP50, brindando las condiciones necesarias para la reactivación del nematodo y que reiniciara su ciclo de vida con el consecuente aumento poblacional.

\section{Sincronización}

El método de sincronización es requerido para trabajar con el nematodo siguiendo el orden de su ciclo de vida, este procedimiento permite eliminar las larvas y quedarse con los huevos, con el fin de empezar los ensayos estando los nematodos en un mismo estadio larvario.

Para este procedimiento se tomaron placas donde se visualizó gran cantidad de huevos, las cuales se lavaron con tampón M9 (3g KH2PO4, 6g NaHPO4, $5 \mathrm{~g} \mathrm{NaCl}, 1 \mathrm{ml}$ de $\mathrm{MgSO} 41 \mathrm{M}$ en un litro de agua destilada) y se recogieron en tubos falcón, los cuales se mantenían en una cubeta con hielo para evitar la eclosión de los huevos, estos eran centrifugados a $3000 \mathrm{rpm}$ por 5 minutos a $4^{\circ} \mathrm{C}$. Posteriormente se eliminó el sobrenadante y se adicionó una solución de hipoclorito de sodio al 12\%, la cual destruye las larvas sin que se vean afectados los huevos, esto se mantuvo durante 10 minutos con intervalos de agitación. Luego se centrifugaron a $3000 \mathrm{rpm}$ por 5 minutos a $4^{\circ} \mathrm{C}$ y nuevamente se eliminó el sobrenadante, este procedimiento se repitió una vez más. Con el fin de eliminar los residuos de hipoclorito se realizaron cuatro lavados con tampón M9 y el residuo final se re-suspendió en $1 \mathrm{ml}$ de tampón M9 y se pasó a cajas petri para la posterior eclosión de los huevos a larvas L1 (19).

\section{Ensayos de longevidad y longitud del cuerpo}

Para el ensayo de longevidad, los nematodos sincronizados en el estadio larvario L1 se cultivaron en cajas de medio NGM/E. coli OP50 a temperatura ambiente hasta que alcanzaron el estadio larvario L4, luego fueron transferidos 15 nematodos por placa cada día hasta finalizar su período reproductivo para evitar mezcla de generaciones, posteriormente solo se transfirieron cada dos días y al cabo de este tiempo se determinó la viabilidad mirando si respondían los nematodos al estímulo con el asa. 
Para el ensayo de longitud del cuerpo los nematodos sincronizados en el estadio larvario L1 se cultivaron en cajas de medio NGM/E. coli OP50 hasta terminar su periodo fértil. En esta etapa de desarrollo se les provocó la muerte por medio de un tratamiento térmico a $42^{\circ} \mathrm{C}$ durante dos horas, para medir su longitud por medio de un microscopio con reglilla milimetrada. Se realizó el conteo de 10 nematodos por ensayo (19). Estos ensayos se llevaron a cabo por triplicado.

\section{Ensayos de reproducción y estrés térmico}

Para el ensayo de reproducción los nematodos sincronizados en el estadio larvario L1 se cultivaron en cajas de medio NGM/E. coli OP50 cuando alcanzaron el estadio larvario L4 se empezó a transferir de a un gusano por día a nuevos medios, esto hasta finalizar su periodo reproductivo. Cada medio con los huevos se dejaba incubar por dos días y luego se hacía el conteo de las larvas en estadios L1 Y L2.

En C. elegans se ha observado que ante condiciones adversas como el estrés térmico las células producen un rápido aumento en las concentraciones de las HSP (por sus siglas en inglés Heat Shock Proteins), las cuales constituyen un mecanismo de defensa que permite a la célula adaptarse a condiciones anómalas y aumentar su capacidad de supervivencia (20).

Para evaluar la viabilidad del nematodo ante el estrés térmico, se llevóo a cabo el ensayo en dos etapas de desarrollo: primero los nematodos sincronizados en el estadio larvario L1 se cultivaron en cajas de medio NGM/E. coli OP50 cuando alcanzaron el primer día de adulto joven se sometieron a $35^{\circ} \mathrm{C}$ durante 8 horas, para el segundo ensayo se esperó a que los nematodos en estadio larvario L1 alcanzaran el sexto día de adulto joven y se sometieron a $35^{\circ} \mathrm{C}$ durante 8 horas, estos desde el cuarto día eran transferidos a nuevas placas para evitar mezcla de generaciones. La viabilidad fue determinada tocando a los nematodos con el asa, si no respondían se consideraban muertos. Este ensayo se realizó con 30 nematodos por triplicado. En la estandarización se sometieron los nematodos a $35^{\circ} \mathrm{C}$ y $37^{\circ} \mathrm{C}$ en las dos etapas (19). Estos ensayos se llevaron a cabo por triplicado.

\section{Análisis estadístico}

Los resultados fueron analizados estadísticamente con el método One-Way y Two-Way Anova que realiza el programa GraphPad Prims Version 5.

\section{Resultados}

La cepa silvestre N2 de C. elegans se reactivó a las 2 horas de ser transferidas al medio de NGM con la E. coli OP50. Inicialmente se observó movimiento de larvas y hacia las 24 horas ya se obtuvo una población sostenida de C. elegans con el inicio de producción de crías, posteriormente, a las 48 horas ya se podía identificar la presencia de varios estadios larvarios, huevos y la eclosión de los mismos (ver Figura 2A).

\section{Identificación de los estados larvarios}

Una vez se obtuvieron los huevos por medio de la sincronización (ver Figura 2B), fueron transferidos al medio NGM y se dejaron por 14 a 16 horas, periodo en donde se llevó a cabo la fase embrionaria del nematodo para la posterior eclosión a la larva L1, caracterizada por un tamańo pequeño que no permite visualizar sus órganos totalmente diferenciados (ver Figura 2C); al cabo de 12 horas se procedió a identificar el estado larvario L2 que presenta un tamańo ligeramente mayor al de la L1 y mayor complejidad a nivel interno (ver Figura 2D). A las 8 horas se identificó el estado larvario L3 (ver Figura 2E) donde se distingue un aumento de tamaño considerable que oscila entre las $600 \mu \mathrm{m}$ y $700 \mu \mathrm{m}$, y sus estructuras internas presentan mayor diferenciación. Después de 16 horas se llega al estado larvario L4 (ver Figura 2F) donde se puede apreciar un espacio o campo claro hacia la mitad del cuerpo que corresponde al lugar donde se almacenarán los huevos; además, su tamaño se acerca a los $1000 \mu \mathrm{m}$. El nematodo alcanzó su estado de adulto joven 10 
horas después de haber alcanzado su estado larvario L4, dando inicio a su etapa reproductiva y alcanzando su madurez 8 horas después. Las diferencias entre el adulto joven y el adulto (ver Figura 2G) pasan desapercibidas; sin embargo, el adulto muestra un ancho y longitud mayor al adulto joven.

\section{Caracterización de longevidad y longitud del} cuerpo de la cepa silvestre N2 de C. elegans

En esta parte del ensayo los nematodos llegaron hasta su madurez y se evitó la mezcla de generaciones para poder evaluar su supervivencia en un periodo de tres a cuatro semanas. En este lapso se encontró que en los primeros 20 días, de los 30 nematodos el 20\% eran viables pues respondieron al estímulo con el asa, el $80 \%$ no presentaban signo de supervivencia, y ya para el día 30 ninguno de los organismos había sobrevivido. Hubo una disminución progresiva de la longevidad con ausencia de supervivencia de la población inicial hacia el día 22. ( ver Figura 3A).

Para determinar la longitud del nematodo, una vez fue sincronizado el cultivo, se permitió que llegaran hasta el final de su periodo fértil, y posteriormente se sometieron temperaturas superiores a $\operatorname{los} 40^{\circ} \mathrm{C}$ con el fin de provocar su muerte y poder determinar la longitud (ver Figura 3B); para este fin, se midieron 10 nematodos determinando que tienen una longitud de $1100 \pm 50 \mu \mathrm{m}$ (ver Figura 3C).

\section{Caracterización de reproducción y estrés térmico de la cepa silvestre N2 de C. elegans}

En cuanto al comportamiento reproductivo, se pudo observar que en los tres ensayos los gusanos empezaban a poner huevos desde el primer día de adulto hasta aproximadamente el cuarto día. Se determinó que el nematodo tuvo una capacidad reproductiva en promedio de 225 crías por ciclo (ver Figura 4A).

Para determinar la supervivencia del nematodo bajo la influencia del estrés térmico se realizó una observación en dos etapas de desarrollo: al primer y sexto día de adulto. Para esta parte del experimento se tomaron 30 larvas en estadio L1, las cuales se transfirieron a medio NGM y se esperó hasta que alcanzaran el primer día de adulto para someterlas durante 8 horas a temperaturas entre $37^{\circ} \mathrm{C}$ y $35^{\circ} \mathrm{C}$; como resultado se pudo observar que el porcentaje de supervivencia fue menor en los nematodos que se sometieron a una temperatura de $37^{\circ} \mathrm{C}$ con una proporción promedio de supervivencia del $17 \%$ y un intervalo que va del16\% al 23\%, esto en comparación a aquellos nematodos que fueron sometidos a temperaturas de $35^{\circ} \mathrm{C}$ con una proporción promedio de $92 \%$ de supervivencia y un intervalo de $90 \%$ a $93 \%$. (ver Figura 4B).

En un segundo ensayo se esperó hasta el final del periodo reproductivo de los nematodos (seis días a partir del estadio de adulto joven). Al sexto día los adultos fueron sometidos durante 8 horas a temperaturas entre $37^{\circ} \mathrm{C}$ y $35^{\circ} \mathrm{C}$. Además, se procedió a contar el número de nematodos vivos y muertos (ver Figura 4B). La proporción promedio de nematodos sobrevivientes fue del $7 \%$ a una temperatura de $37^{\circ} \mathrm{C}$ con un intervalo de $4 \%$ a $10 \%$ y del $84 \%$ a una temperatura de $35^{\circ} \mathrm{C}$ con un intervalo de $83 \%$ a $86 \%$. En las dos etapas de desarrollo se pudo ver que a una temperatura de $37^{\circ} \mathrm{C}$ el porcentaje de supervivencia es muy bajo comparado con una temperatura de $35^{\circ} \mathrm{C}$. También se determinó que son más resistentes en el primer día que en el sexto día de adulto y esto se evidenció tanto a temperaturas de $37^{\circ} \mathrm{C}$ como a $35^{\circ} \mathrm{C}$, puesto que al primer día de adulto fueron sometidos a temperaturas de $37^{\circ} \mathrm{C}$ y se obtuvo un $17 \%$ de supervivencia mientras que al sexto día solamente un $9 \%$ de los nematodos que sobrevivieron cuando fueron expuestos a la misma temperatura, lo mismo se evidenció en el ensayo que se realizó a temperaturas de $35^{\circ} \mathrm{C}$ con un $92 \%$ de supervivencia al primer día de adulto y un $84 \%$ de supervivencia al sexto día de adulto. 


\section{Discusión}

Uno de los factores que hacen relevante el uso de C. elegans como modelo biológico es el ciclo corto de vida (3 días) y gran número de progenies (hasta $300)$, lo que permite la producción a gran escala de los animales dentro de un corto periodo de tiempo (8). De acuerdo con $\mathrm{Hu}$ y colaboradores en el 2007, una reactivación exitosa del cultivo consiste en que una vez proporcionadas las condiciones óptimas al nematodo en etapa de quiescencia o dauer, este reactivaría su ciclo de vida llegando a su etapa adulta en un tiempo de 15 horas post-instauración de las condiciones ambientales (21), tal como se ha podido ver a lo largo de este estudio.

Son pocos los estudios que abordan la caracterización de los distintos estadios larvarios de C. elegans. El punto de partida es el trabajo publicado por Hall y colaboradores en el 2007 en el atlas de C. elegans; donde describen los estadios larvarios de acuerdo a su complejidad tanto interna como externa, lo cual contribuyó bastante a la descripción dada por este estudio, pues las larvas se pudieron identificar tanto por tamaño como por el desarrollo interno de las mismas (22).

La longevidad evaluada en el experimento con la cepa N2 coincide con la descripción del ciclo de vida natural de la cepa, en el cual se dice que el C. elegans $\mathrm{N} 2$ tiene un periodo de vida de aproximadamente tres semanas y que los individuos de una población no mueren al tiempo sino que la población va disminuyendo paulatinamente (23). Surcos-laos y colaboradores en el 2011, utilizaron como control la cepa N2 para sus estudios del efecto de quercertina en el C. elegans, en el ensayo de longevidad se mostró que hacia los días 20 y 21 de vida la cepa disminuía su supervivencia a un $20 \%$ y hacia el día 30 un $0 \%$, lo cual se relaciona con el resultado del ensayo realizado en este estudio, igualmente demuestra la inequidad en los tiempos de mortalidad de cada individuo de la población (19). Win y colaboradores en el 2013 estudiaron la longevidad de la cepa N2 y de las cepas mutan- tes mu86 y mgDf50 comparando la supervivencia de estos medios con E. coli OP50 activa y medios con la misma inactiva mediante luz UV, demostrando que la cepa N2 en condiciones normales de mantenimiento durante los días 20 y 21 tiene una supervivencia que oscila entre el $10 \%$ y el $20 \%$, e igualmente los resultados de los ensayos realizados hacia el día 30 la supervivencia era de un $0 \%$ (24).

La longitud del nematodo en los experimentos realizados osciló en un rango de $1100 \pm 50 \mu \mathrm{m}$ dato que se asemeja a lo reportado en la literatura. C. elegans tiene una longitud de aproximadamente $1000 \mu \mathrm{m}$ en su etapa adulta (25). Mörck y Pilo estudiaron en 2006 la cepa N2 junto con cepas mutantes (dbl-1, eat-3, pha-2, pha-3,sma-1 y tax-6) debido a que estas cepas poseían mutaciones que causaban defectos en el proceso de alimentación del nematodo la cual está relacionada con el crecimiento del mismo. En este estudio la cepa N2 mostró una longitud promedio de $1200 \pm 100 \mu \mathrm{m}$, lo cual coincide con los resultados presentados en este trabajo (26). Por otro lado, Knigth y colaboradores en 2002 estudiaron el crecimiento en la cepa N2 midiendo al nematodo en cada una de sus etapas larvarias y relacionándolo con el proceso de división y diferenciación celular que este tiene durante el transcurso de estas etapas. En ese estudio encontraron que el nematodo adulto presentaba una longitud promedio de $1500 \pm 400 \mu \mathrm{m}$, un valor aproximado pero alto comparado con los resultados del este estudio, lo que puede deberse a las diversas metodologías empleadas, cuyo fundamento y proceso difieren entre sí.

Gualteros Bustos y colaboradores en 2017 realizaron la medición en los nematodos inmovilizados con levamisol $100 \mathrm{mM}$ (14), mientras que Laos y colaboradores en 2011, utilizaron una fuente térmica (horno) a 42OC durante dos horas con el fin de ocasionar la muerte de los nematodos y así facilitar su medición por medio de un software de procesamiento de datos equipado de una escala milimetrada (27), similar a la empleada en este estudio. 
La caracterización de C. elegans realizada en el presente estudio partió de un promedio de comportamiento reproductivo de 225 progenies que está dentro de los valores de número y de tamaño de progenies normalizado.

En el nematodo C. elegans la respuesta de choque térmico es regulada por una red de neuronas termosensoriales que detectan temperaturas elevadas y activan un mecanismo de proteccion que permite la restauracion de la homeostasis (28), siendo esta vía de respuesta conservada evolutivamente. En este estudio se determinó que la supervivencia evaluada en las dos etapas de desarrollo del nematodo es muy reducida a $37^{\circ} \mathrm{C}$, en comparacion de $35^{\circ} \mathrm{C}$. Además, los nematodos fueron más resistentes al primer día de adulto joven en comparacion con el sexto día de adulto. Esto se puede explicar debido a que a mayor edad las células sufren atenuación a la respuesta de shock térmico, lo cual conduce a la acumulacion de proteinas dańadas (29).

El C. elegans como modelo de experimentos biológicos es importante en la actualidad ya que no solo es un modelo simple de trabajar debido a su susceptibilidad experimental, sino que presenta gran similitud genética con el ser humano (31); además, tiene un sistema nervioso bien definido lo cual lo hace un modelo interesante en los estudio de neurociencias. Desde su descubrimiento ha sido utilizado no solo para el entendimiento del proceso fisiopatológico de las distintas patologías, sino como modelo inicial para el tamizaje de nuevos tratamientos y la identificación de nuevos blancos terapéuticos (30-31). En Colombia al no haber muchos estudios utilizando este modelo, el uso de este en nuevas investigaciones abre un nuevo campo de acción el entendimiento de las enfermedades neurodegenerativas y patologías de otra índole.

\section{Agradecimientos}

Agradecimientos a Coronel Robayo CD, y Tovar Bohórquez JT por su colaboración en el desarrollo experimental del estudio. Este trabajo fue apoyado por la Universidad Colegio Mayor de Cundinamarca. A la Dra. Andrea Calixto de la Universidad Mayor de Chile por la donación de la cepa N2 de C. elegans y E. coli OP50.

\section{Figuras}

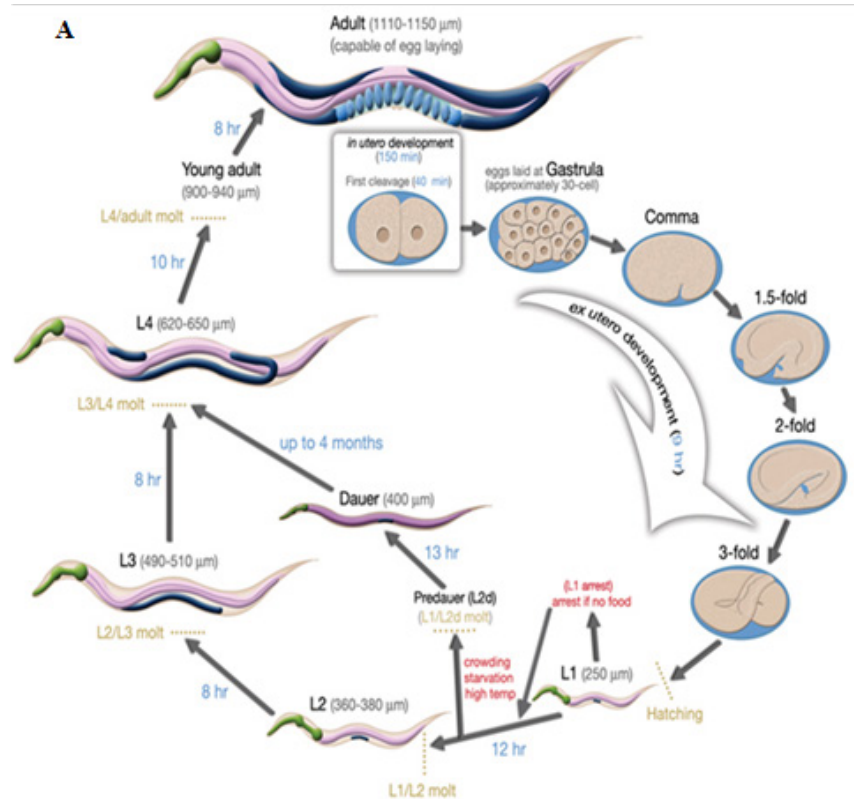

B

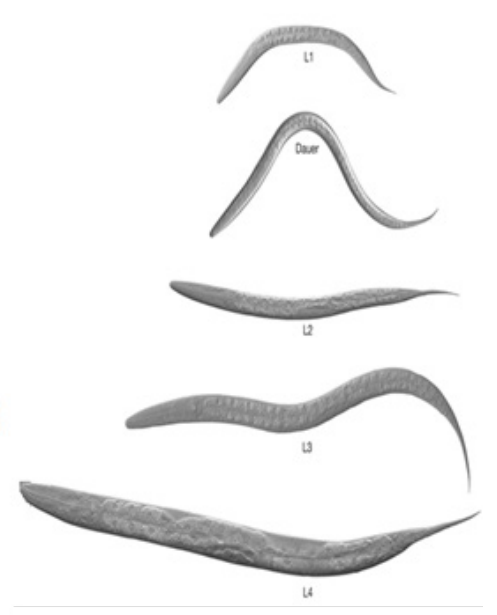

Figura 1. Ciclo de vida de la cepa silvestre N2. A. Ciclo de vida de la cepa silvestre N2. B. Características fenotípicas de los estadios larvarios de la cepa silvestre N2. Fotografías tomadas del Worm Atlas copyright 2016. 
A

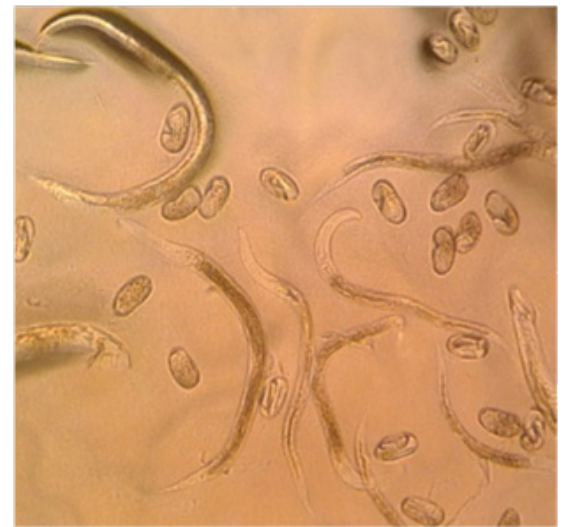

B

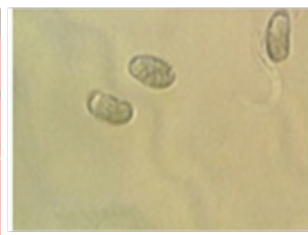

$\mathbf{E}$

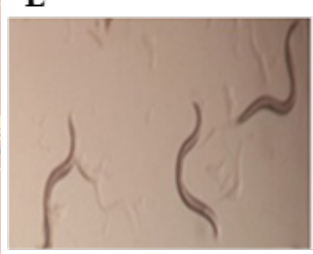

C

D

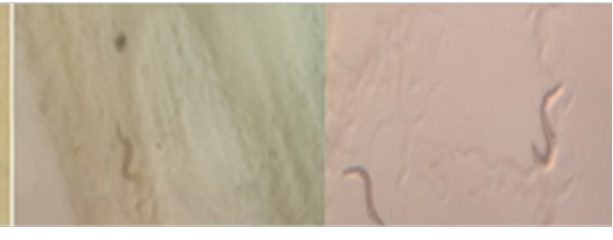

F

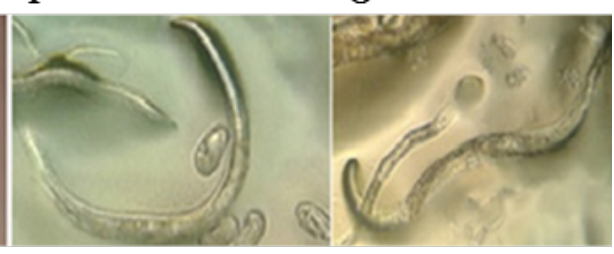

Figura 2. Estandarización del cultivo y caracterización fenotípica de la cepa silvestre N2. A. Cultivo 48 horas postransferencia de agar ya hay presencia de larvas L4 y puesta de crías al igual que otros estadios larvarios. Estadios larvarios de C. elegans. B. Huevos de C. elegans post-sincronización. C. Larva L1 16 - 24 horas post-sincronización. D. Larva L2 36 horas post-sincronización. E. Larva L3 44 horas post-sincronización. F. Larva L4 60 horas post-sincronización. G. Adulto joven 68 horas post sincronización. Fotografías tomada por Caren Dayan Coronel Robayo.

A
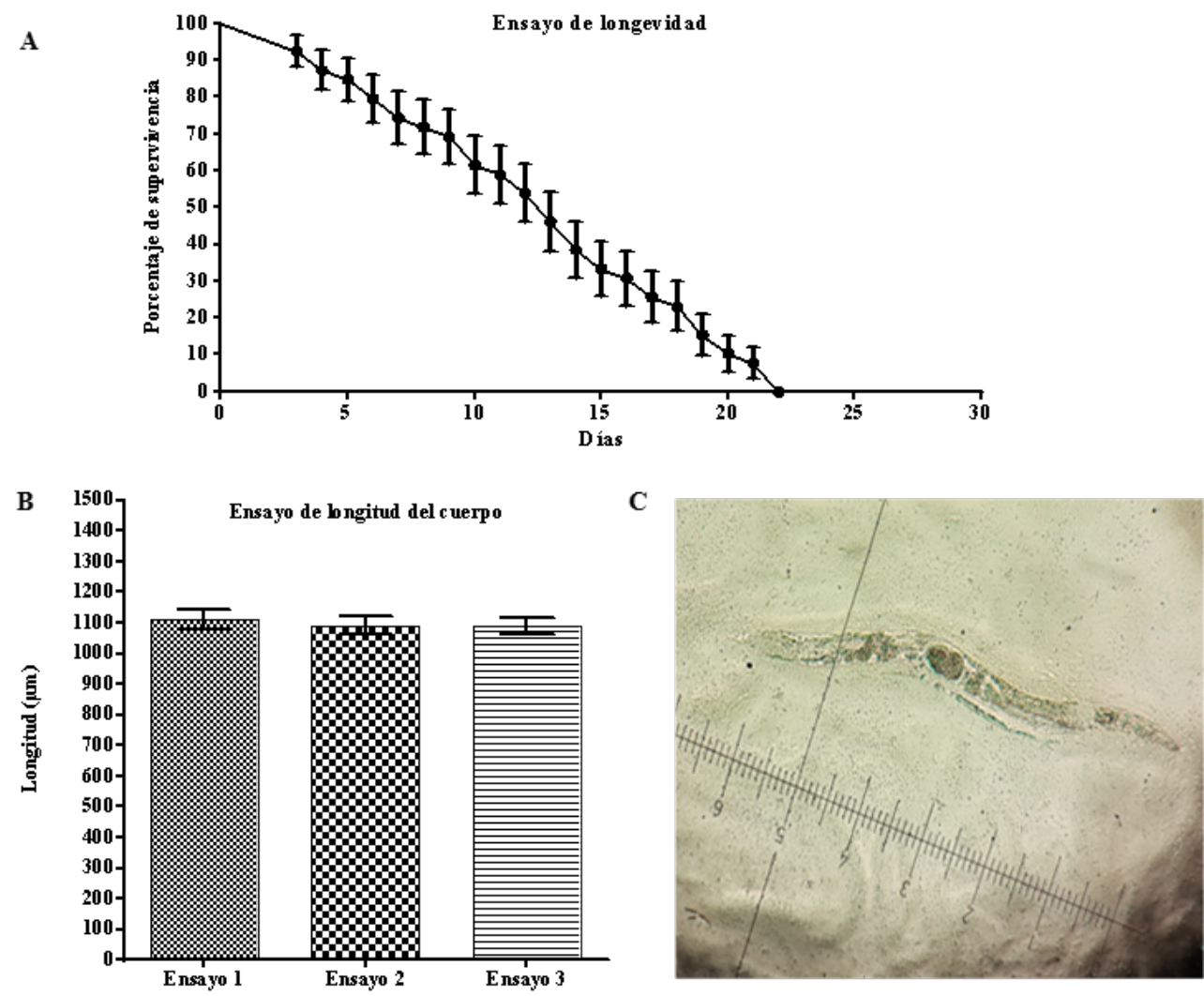

Figura 3. Longevidad y longitud de la cepa silvestres N2 de C. elegans. A. Disminución progresiva de la longevidad con ausencia de supervivencia de la población inicial hacia el día 22. Los ensayos se presentan como la media de tres experimentos independientes. $\mathrm{P}<0.0001$. B. Se muestra la media de los tres ensayos donde se puede estimar que la longitud del nematodo al finalizar su periodo de fertilidad es de $1100 \pm 50 \mu \mathrm{m}$. Los ensayos se presentan como la media de tres experimentos independientes. P<0,2159. C. Adulto joven después del tratamiento a $40^{\circ} \mathrm{C}$ en su medición con retícula objetivo de 10x. Fotografía tomada por Caren Dayan Coronel Robayo. 
A

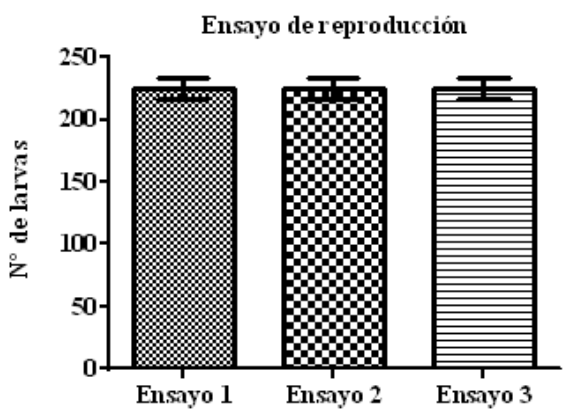

C

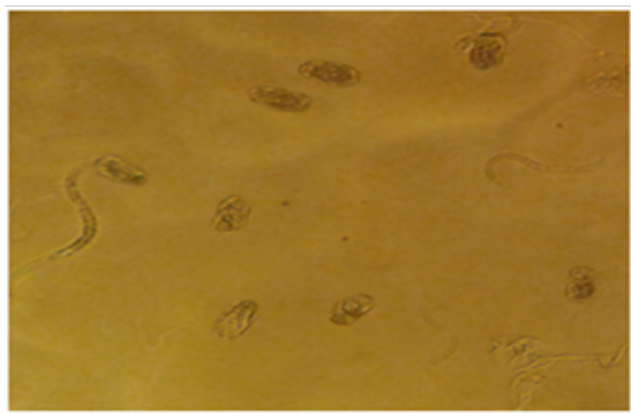

B

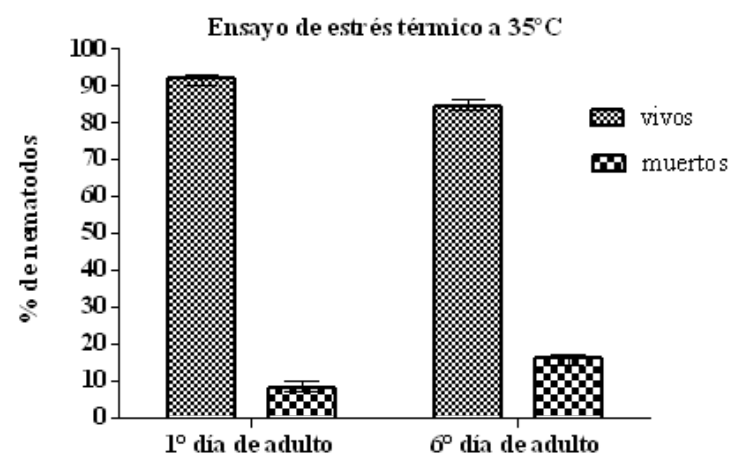

D

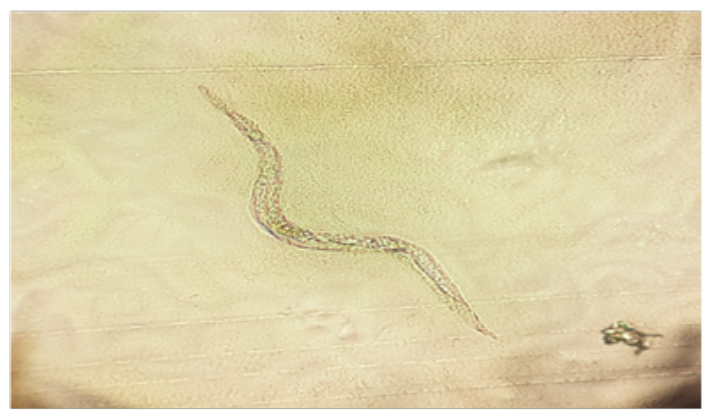

Figura 4. Ensayo de reproducción y estrés térmico de la cepa silvestre N2 de C. elegans. A. Se observa el comportamiento reproductivo de C. elegans en el que se tiene un promedio de 225 progenies. Ensayos realizados por triplicado. Los tres ensayos no mostraron diferencia estadística representativa ya que fueron constantes. $\mathrm{P}<1.0000$. B. Se muestra la viabilidad de los nemátodos bajo la influencia del estrés térmico a $35^{\circ} \mathrm{C}$. Se determinó que son más resistentes al primer día de adulto joven. Los ensayos se presentan como la media de tres experimentos independientes. $\mathrm{P}<0.0003$. C. Conteo de larvas en el primer día reproductivo del nematodo objetivo de $10 \mathrm{x}$ se pueden observar huevos. D. Adulto Joven después del tratamiento a $35^{\circ} \mathrm{C}$ el cual no responde al estímulo con el asa en objetivo $10 x$. Fotografías tomadas por Caren Dayan Coronel Robayo.

\section{Referencias}

1. Van Ham TJ, Thijssen KL, Breitling R, Hofstra RM, Plasterk RH, Nollen EA. C. elegans model identifies genetic modifiers of alpha-synuclein inclusion formation during aging. PLoS genetics. 2008;4(3):e1000027.

2. Locke C, Berry K, Kautu B, Lee K, Caldwell K, Caldwell G. Paradigms for pharmacological characterization of C. elegans synaptic transmission mutants. Journal of visualized experiments : JoVE. 2008(18).

3. Qian H, Robertson AP, Powell-Coffman JA, Martin RJ. Levamisole resistance resolved at the single-channel level in Caenorhabditis elegans. FASEB journal : official publication of the Federation of American Societies for Experimental Biology. 2008;22(9):3247-54.

4. Daigle I, Li C. apl-1, a Caenorhabditis elegans gene encoding a protein related to the human beta-amyloid protein precursor. Proceedings of the National Academy of Sciences of the United States of America. 1993;90(24):12045-9.
5. Kraemer BC, Zhang B, Leverenz JB, Thomas JH, Trojanowski JQ, Schellenberg GD. Neurodegeneration and defective neurotransmission in a Caenorhabditis elegans model of tauopathy. Proceedings of the National Academy of Sciences of the United States of America. 2003;100(17):9980-5.

6. Nass R, Hahn MK, Jessen T, McDonald PW, Carvelli L, Blakely RD. A genetic screen in Caenorhabditis elegans for dopamine neuron insensitivity to 6-hydroxydopamine identifies dopamine transporter mutants impacting transporter biosynthesis and trafficking. Journal of neurochemistry. 2005;94(3):774-85.

7. Voisine C, Varma H, Walker N, Bates EA, Stockwell BR, Hart AC. Identification of potential therapeutic drugs for huntington's disease using Caenorhabditis elegans. PloS one. 2007;2(6):e504.

8. Leung MC, Williams PL, Benedetto A, Au C, Helmcke KJ, Aschner $\mathrm{M}$, et al. Caenorhabditis elegans: an emerging model in biomedical and environmental toxicology. Toxicological sciences : an official journal of the Society of Toxicology. 2008;106(1):528. 
9. Dostal V, Link CD. Assaying beta-amyloid toxicity using a transgenic C. elegans model. Journal of visualized experiments : JoVE. 2010(44).

10. Nass R, Miller DM, Blakely RD. C. elegans: a novel pharmacogenetic model to study Parkinson's disease. Parkinsonism \& related disorders. 2001;7(3):185-91.

11. Berkowitz LA, Hamamichi S, Knight AL, Harrington AJ, Caldwell GA, Caldwell KA. Application of a C. elegans dopamine neuron degeneration assay for the validation of potential Parkinson's disease genes. Journal of visualized experiments : JoVE. 2008(17)

12. Wolozin B, Saha S, Guillily M, Ferree A, Riley M. Investigating convergent actions of genes linked to familial Parkinson's disease. Neuro-degenerative diseases. 2008;5(3-4):182-5.

13. Dexter PM, Caldwell KA, Caldwell GA. A predictable worm: application of Caenorhabditis elegans for mechanistic investigation of movement disorders. Neurotherapeutics : the journal of the American Society for Experimental NeuroTherapeutics. 2012;9(2):393-404.

14. Bustos AVG, Jiménez MG, Mora RMS. The Annona muricata leaf ethanol extract affects mobility and reproduction in mutant strain NB327 Caenorhabditis elegans. Biochemistry and Biophysics Reports. 2017;10:282-6.

15. Sulston JE, Schierenberg E, White JG, Thomson JN. The embryonic cell lineage of the nematode Caenorhabditis elegans. Developmental biology. 1983;100(1):64-119.

16. Kaletta T, Hengartner MO. Finding function in novel targets: C. elegans as a model organism. Nat Rev Drug Discov. 2006;5(5):387-99.

17. Dimitriadi M, Hart AC. Neurodegenerative disorders: insights from the nematode Caenorhabditis elegans. Neurobiology of disease. 2010;40(1):4-11.

18. Stiernagle T. Maintenance of C. elegans. University of Minnesota1999.

19. Surco-Laos F, Cabello J, Gomez-Orte E, Gonzalez-Manzano S, Gonzalez-Paramas AM, Santos-Buelga C, et al. Effects of O-methylated metabolites of quercetin on oxidative stress, thermotolerance, lifespan and bioavailability on Caenorhabditis elegans. Food \& function. 2011;2(8):445-56.

20. Chávez Zobel AT, Sáenz Suárez H. Implicaciones de las proteínas de choque térmico ( $\mathrm{H} \mathrm{H}$ s/HSPB) en el desarrollo de enfermedades degenerativas. Universitas Scientiarum. 2009;14(1):12.

21. Zaidel-Bar R, Miller S, Kaminsky R, Broday L. Molting-specific downregulation of $\mathrm{C}$. elegans body-wall muscle attachment sites: the role of RNF-5 E3 ligase. Biochemical and biophysical research communications. 2010;395(4):509-14.

22. Nance J, Priess JR. Cell polarity and gastrulation in C. elegans. Development. 2002;129(2):387-97.

23. Riddle DL, Blumenthal T, Meyer BJ. C. elegans II: Section II, Origins of the Model. Cold Spring Harbor (NY):. 2nd ed. Cold Spring Harbor Laboratory1997.
24. Win MT, Yamamoto Y, Munesue S, Han D, Harada S, Yamamoto H. Validated Liquid Culture Monitoring System for Lifespan Extension of Caenorhabditis elegans through Genetic and Dietary Manipulations. Aging and disease. 2013;4(4):178-85.

25. Barriere A, Felix MA. Natural variation and population genetics of Caenorhabditis elegans. WormBook : the online review of C elegans biology. 2005:1-19.

26. Morck C, Pilon M. C. elegans feeding defective mutants have shorter body lengths and increased autophagy. BMC developmental biology. 2006;6:39.

27. Laos FAS. Evaluación de la actividad de flavonoides y sus metabolitos en el organismo modelo Caenorhabditis elegans. Universidad de salamanca - facultad de farmacia; Departamento de Química Analítica, Nutrición y Bromatología. 2011. Epub 2011.

28. Maman M, Carvalhal Marques F, Volovik Y, Dubnikov T, Bejerano-Sagie M, Cohen E. A neuronal GPCR is critical for the induction of the heat shock response in the nematode $\mathrm{C}$. elegans. The Journal of neuroscience : the official journal of the Society for Neuroscience. 2013;33(14):6102-11.

29. Verbeke P, Fonager J, Clark BF, Rattan SI. Heat shock response and ageing: mechanisms and applications. Cell biology international. 2001;25(9):845-57.

30. Sengupta P, Samuel AD. Caenorhabditis elegans: a model system for systems neuroscience. Current opinion in neurobiology. 2009;19(6):637-43.

31. Flórez, R. A. N. Avances y perspectivas en Síndrome de Asperger. 2014; Nova, 12(21). 